\title{
Drop-out rate among patients treated with omalizumab for severe asthma: Literature review and real-life experience
}

\author{
M. Caminati ${ }^{*}$, G. Senna ${ }^{1}$, G. Stefanizzi ${ }^{1}$, R. Bellamoli', S. Longhi' , F. Chieco-Bianchi' ${ }^{2}$, G. Guarnieri ${ }^{3}$, S. Tognella ${ }^{4}$,

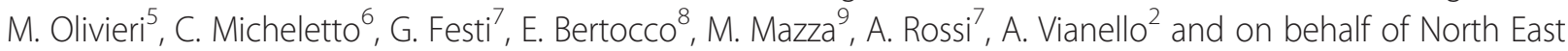 \\ Omalizumab Network study group
}

\begin{abstract}
Background: In patients with asthma, particularly severe asthma, poor adherence to inhaled drugs negatively affects the achievement of disease control. A better adherence rate is expected in the case of injected drugs, such as omalizumab, as they are administered only in a hospital setting. However, adherence to omalizumab has never been systematically investigated. The aim of this study was to review the omalizumab drop-out rate in randomized controlled trials (RCTs) and real-life studies. A comparative analysis was performed between published data and the Italian North East Omalizumab Network (NEONet) database.

Results: In RCTs the drop-out rate ranged from 7.1 to $19.4 \%$. Although the reasons for withdrawal were only occasionally reported, patient decision and adverse events were the most frequently reported causes. In real-life studies the drop-out rate ranged from 0 to $45.5 \%$. In most cases lack of efficacy was responsible for treatment discontinuation. According to NEONet data, $32 \%$ of treated patients dropped out, with an increasing number of drop outs observed over time. Patient decision and lack of efficacy accounted for most treatment withdrawals.

Conclusions: Treatment adherence is particularly crucial in patients with severe asthma considering the clinical impact of the disease and the cost of non-adherence. The risk of treatment discontinuation has to be carefully considered both in the experimental and real-life settings. Increased knowledge regarding the main reasons for patient withdrawal is important to improve adherence in clinical practice.
\end{abstract}

Keywords: Drop-out, Adherence, Severe asthma, Omalizumab

Abbreviations: EMA, European Medicines Agency; FEV 1 , Forced expiratory volume in 1 s; GETE, Global evaluation of treatment effectiveness; IgE, Immunoglobulin E; NEONet, North East Omalizumab Network; RCT, Randomized clinical trial

\section{Background}

Adherence is usually defined as the extent to which the patient's use of medication matches the prescribed regimen. Poor adherence has a critical relevance in the management of various chronic diseases as it may negatively affect treatment outcomes and result in increased hospitalizations, morbidity, and mortality [1]. In bronchial asthma the

\footnotetext{
*Correspondence: ma.caminati@gmail.com

${ }^{1}$ Asthma Center and Allergy Unit, Verona General and University Hospital, Verona, Italy

Full list of author information is available at the end of the article
}

achievement of disease control is closely related to adherence. It has been extensively demonstrated that an irregular drug intake markedly affects patient's quality of life, as it is responsible for an increased risk of nocturnal awakenings and impairment in routine daily activities, such as exercise and sports [2].

Lack of adherence is very common, particularly in chronic conditions [3-7]. In fact, the treatment discontinuation rate ranges from 20 to $40 \%$ for acute illnesses and from 30 to $60 \%$ for chronic diseases. Preventive treatments are associated with a non-adherence rate of up to $80 \%$ [8]. As far as asthma is concerned, it is well known that about $50 \%$ of patients are non-adherent. 
The issue becomes even more relevant in specific age groups such as children, adolescents and elderly [9].

A number of factors, including fear of treatment-related side effects, poor perception of symptoms, belief in alternative/complementary medicine but also complex treatment regimens, illness-related factors, inconvenience, and social background, may account for poor adherence, which has a very high social cost [1]. In the United States, irregular drug intake among patients with hypertension is responsible for 89 premature deaths every year [10]. It is estimated that annually \$US100 billion which is spent on unnecessary or preventable hospitalizations related to poor adherence could be saved [11].

Many of the above mentioned variables have been described as determinants of poor adherence to asthma treatments. Also, poor awareness of the need for treatment even in the absence of symptoms and steroids fear are two main reasons for treatment withdrawal in asthmatic patients [12]. On the other side, caregivers themselves have to face some limitations such as difficulties in patients follow-up scheduling and time constraints, which may hamper patient's adherence support [9].

A univocal and standardized tool for evaluation of adherence is lacking. Although many methods are currently available none of them can be considered as the gold standard [1]. Another controversial aspect concerns the definition of "acceptable adherence". In some large studies, an adherence rate greater than $80 \%$ has been considered satisfactory [1] but a general consensus about this issue has not been reached.

In bronchial asthma evaluation of adherence is even more difficult as treatment is mainly based on inhaled drugs. In this case, an objective adherence evaluation may rely on different tools but due to many limitations with these tools their use in routine clinical practice is not suitable. Electronic devices are accurate but are also quite expensive [13]; therefore recording of pharmacy refills can be considered as a more affordable option but they are less accurate. Patients usually deny any lack of adherence, even in severe asthma [14].

Treatment discontinuation is one of the most relevant aspects of adherence, as it leads to major consequences. From this perspective, drop-out rate can be considered to be a surrogate marker of adherence. In randomized controlled trials (RCTs) a high drop-out rate can weaken the final results [15], and in the real-life setting it is related to preventable patient impairments and unnecessary costs. Furthermore, the detection and quantification of drop-out rate in a daily clinical setting is a complex issue, as regular follow-up for all patients is not always possible. Patients requiring treatment with injected drugs are more easily monitored, as treatment administration requires medical supervision. This is the case with omalizumab, an antiimmunoglobulin E (IgE) monoclonal antibody for the treatment of severe asthma. It must be administered in a hospital setting once or twice a month, according to the patient's total IgE level [16]. Thus, treatment discontinuation can be easily detected and considered as a consistent marker of adherence.

To our knowledge, the treatment discontinuation rate among patients undergoing omalizumab treatment has never been systematically investigated as a primary outcome. The present study aimed to review the drop-out rate and describe the most common reasons for patient withdrawal in RCTs and real-life studies published up to December 2014. A comparative analysis between published data and an Italian database, the North East Omalizumab Network (NEONet), was also conducted.

\section{Methods}

\section{Search strategy}

A complete search of the Cochrane Central Register of Controlled Trials (CENTRAL) in the Cochrane Library, MEDLINE and PubMed up to December 2014 was carried out. The search strategy retrieved citations containing the subject heading "omalizumab" and was restricted to randomized, double-blind, placebo-controlled trials and "real life studies" for severe allergic asthma in patients aged $\geq 18$ years old. The keywords used were: omalizumab, asthma, controlled studies, randomized trial, real life studies, pragmatic studies. All retrieved studies were restricted to the English language.

\section{Italian North East Omalizumab Network (NEONet) database analysis}

A retrospective analysis of the NEONet database was carried out. Details about the Network and the data collecting methods are provided elsewhere [17]. In brief, NEONet is a non-profit project approved by the local ethics committee and involves 19 Allergy and Respiratory Referral Centres for Severe Asthma located in the NorthEast region of Italy. It aims to collect an extensive amount of clinical data on patients undergoing omalizumab treatment in a real-life setting and provide some new insights concerning current unmet needs (e.g. impact of omalizumab treatment on lung function and on asthma comorbidities, long-term follow-up of treated patients, adherence, non-responders profile, optimal treatment duration). The participating clinicians enter anonymous coded data into a shared limited-access web platform.

\section{Drop-out evaluation}

The drop-out rate and the most common reasons for treatment discontinuation were evaluated, if reported, in RCT, in "real life studies" and in the NEONet database. Reasons for withdrawal were categorized as follows: patient's decision, lack of efficacy, adverse event, clinical efficacy, and other causes. With regard to the NEONet 
database, "lack of efficacy" and "clinical efficacy" were defined according to the GETE (global evaluation of treatment effectiveness) Questionnaire [18], which was completed by physicians for every patient. GETE is a five-point scale: 1 is excellent (complete control of asthma), 2 is good (marked improvement), 3 is moderate (discernible, but limited improvement), 4 is poor (no appreciable change), and 5 is worsening. Number 4 and 5 corresponded to "lack of efficacy" and number 1 and 2 corresponded to "clinical efficacy".

\section{Statistical analysis}

Two-sample t-test was used to compare the variables in Table 4. Two-proportion z-test was used to analyze the differences between mean drop-out rates and reasons. All tests have been performed with a significance level of $5 \%$. A logistic regression analysis was provided in order to verify the association between drop-out rate and treatment duration. R software has been used.

\section{Results}

Randomized controlled studies (RCTs)

As of December 2014, seven RCTs have been published (Table 1) [16, 19-24]. Overall, 1719 patients were included, with a slightly higher prevalence of females. Across the studies, the mean age ranged from 37.5 to 43.7 years. The drop-out rate, which was reported in all the analyzed studies, ranged from 7.1 to $19.4 \%$. However, reasons for withdrawal were not always reported. Patient's decision accounted for the majority of drop outs in four of the selected studies [16, 20, 21, 24]; whereas in two studies adverse events were the main cause of treatment discontinuation [19, 22]. No data were available with regard to the timing of drop-outs after the initiation of treatment.

\section{Real-life studies}

As of December 2014, 19 real-life studies have been published on the use of omalizumab in severe asthma (Table 2) [25-42]. A total of 13,466 patients were included: compared with RCTs the age range was broader in real-life studies (29.5 to 49.9 years) with the inclusion of patients aged almost 10 years younger and 6 years older than RCT patients. The mean study duration was longer in real-life studies.

In the 13 studies that reported the drop-out rate, it ranged from 0 to $45.5 \%$. No patients discontinued treatment in four of these studies [27, 36, 38, 39]. There was notable variability in the reasons given for discontinuing treatment across the different studies. Lack of efficacy was the most common reason for treatment discontinuation in most studies [29, 34, 37, 40]. Patient decision to discontinue treatment was the main reason for drop outs in two studies $[25,28]$ and adverse events were the most frequent reason for withdrawal in one study [37].

\section{Comparison between RCTs and Real-life studies}

Table 3 provides a direct comparison of drop-out rates and reasons between RCTs and Real-life studies. Overall, drop-out rate in Real-life studies is significantly higher. The proportion of patients who discontinued omalizumab due to a lack of efficacy was significantly bigger in real-life studies than in RCTs. On the opposite patient's decision and adverse events have more relevance in RCTs in comparison with Real-life studies.

\section{NEONet database}

The NEONet database included 221 patients. As shown in Table 4, among them 70 (32\%) dropped out; under treatment population and drop-outs did not significantly differ in terms of age, gender and mean treatment duration. Treatment discontinuation was more common amongst females (64\%). Patient decision accounted for most of the withdrawals (49\%), followed by a lack of efficacy (26\%). Within the group of patients droppingout for "onset of contraindications", pregnancy was the reason in all the cases. As far as adverse events is concerned, 3 cases of generalized urticarial have been described; arthralgia and myocarditis have been recorded in two other cases.

Table 5 provides a comparative overview of NEONet database and published Real-life studies in terms of

Table 1 Overall dropout rate and main reasons for treatment discontinuation in RCT

\begin{tabular}{|c|c|c|c|c|c|c|c|c|c|}
\hline Author [ref] & $\mathrm{N}$ & $\begin{array}{l}\text { duration } \\
\text { (months) }\end{array}$ & $\begin{array}{l}\text { Mean } \pm S D \\
\text { age, years }\end{array}$ & $\begin{array}{l}\text { M/F } \\
\text { Ratio }\end{array}$ & $\begin{array}{l}\text { Drop-out } \\
\text { rate }(\%)\end{array}$ & $\begin{array}{l}\text { Patient } \\
\text { decision (\%) }\end{array}$ & $\begin{array}{l}\text { Lack of } \\
\text { efficacy (\%) }\end{array}$ & $\begin{array}{l}\text { Adverse } \\
\text { events (\%) }\end{array}$ & $\begin{array}{l}\text { Other } \\
\text { Causes (\%) }\end{array}$ \\
\hline Busse et al. 2001 [16] & 268 & 7 & 39.3 & 0.63 & 7.1 & 4.1 & 0.37 & 0.74 & 1.49 \\
\hline Soler et al. 2011 [23] & 274 & 7 & 40.0 & 1.06 & 6.9 & 1.09 & 1.09 & NR & NR \\
\hline Holgate et al. 2004 [21] & 126 & 8 & 41.1 & 0.55 & 8.7 & 8.7 & NR & NR & NR \\
\hline Ayres et al. 2004 [19] & 206 & 12 & 37.5 & 0.39 & 7.3 & NR & NR & 7.3 & NR \\
\hline Vignola et al. 2004 [24] & 209 & 7 & $38.3 \pm 14.7$ & 0.92 & 8.1 & 8.1 & NR & NR & NR \\
\hline Humbert et al 2005 [22] & 209 & 7 & $43.4 \pm 13.3$ & 0.48 & 12.2 & NR & NR & 4.5 & NR \\
\hline Hanania et al. 2011 [20] & 427 & 12 & $43.7 \pm 14.3$ & 0.63 & 19.4 & 11.00 & NR & 3.74 & 4.68 \\
\hline
\end{tabular}

$F$ female, $M$ male, NR not reported, $R C T$ randomized controlled trials, SD standard deviation 
Table 2 Overall dropout rate and main reasons for treatment discontinuation in real-life studies

\begin{tabular}{|c|c|c|c|c|c|c|c|c|c|}
\hline Author [ref] & N & $\begin{array}{l}\text { duration } \\
\text { (months) }\end{array}$ & $\begin{array}{l}\text { Mean } \pm S D \\
\text { age, years }\end{array}$ & $\begin{array}{l}\text { M/F } \\
\text { Ratio }\end{array}$ & $\begin{array}{l}\text { Drop-out } \\
\text { rate }(\%)\end{array}$ & $\begin{array}{l}\text { Patient } \\
\text { decision (\%) }\end{array}$ & $\begin{array}{l}\text { Lack of } \\
\text { efficacy (\%) }\end{array}$ & $\begin{array}{l}\text { Adverse } \\
\text { events (\%) }\end{array}$ & $\begin{array}{l}\text { Other } \\
\text { Causes (\%) }\end{array}$ \\
\hline Molimard et al. 2008 [37] & 146 & 12 & $46.5 \pm 13.5$ & 0.57 & 30.6 & 1.4 & 19 & 5.4 & 4.8 \\
\hline Brusselle et al. 2009 [29] & 158 & 12 & $48.1 \pm 17.1$ & 0.85 & 45.5 & 10.1 & 13.3 & 12 & 10.1 \\
\hline Korn et al. 2009 [34] & 280 & 5 & $43.9 \pm 16.3$ & 1.45 & 32.5 & NR & 14.28 & NR & NR \\
\hline Bavbek et al. 2010 [27] & 18 & 6 & $41.8 \pm 11.2$ & 0.63 & 0 & NR & $N R$ & $N R$ & $N R$ \\
\hline Cazzola et al. 2010 [30] & 142 & 24 & $49.6 \pm 4.1$ & 1 & 8.5 & 2.11 & 1.4 & 1.4 & 3.5 \\
\hline Tzortzaki et al. 2012 [39] & 60 & 26 & $54.0 \pm 14.0$ & 0.66 & 0 & NR & $N R$ & $N R$ & $N R$ \\
\hline Wittchen et al. 2012 [42] & 53 & 24 & $48.3 \pm 13.7$ & 1 & $N R$ & $N R$ & $N R$ & NR & NR \\
\hline Vennera M et al. 2012 [40] & 266 & 15 & $51.0 \pm 13.7$ & 0.45 & 18.7 & 5.6 & 10.5 & 2.6 & $N R$ \\
\hline Lafeuille et al. 2012 [35] & 644 & 24 & $49.9 \pm 14.2$ & 0.69 & NR & $N R$ & NR & NR & NR \\
\hline Eisner et al. 2012 [32] & 4969 & 12 & $44.5 \pm 16.6$ & 0.56 & NR & NR & $N R$ & NR & NR \\
\hline Chen et al. 2013 [31] & 4970 & 48 & $44.5 \pm 16.6$ & 0.56 & $N R$ & $N R$ & NR & NR & NR \\
\hline Grimaldi-Bensouda et al. 2013 [33] & 374 & 36 & $49.7 \pm 14.6$ & 0.58 & NR & NR & $N R$ & $N R$ & NR \\
\hline Barnes et al. 2013 [26] & 136 & 36 & $41.3 \pm 14.5$ & 0.46 & $N R$ & NR & $N R$ & NR & $N R$ \\
\hline Maselli et al. 2013 [36] & 26 & 6 & $29.6 \pm 18.7$ & 1.6 & 0 & NR & NR & $N R$ & NR \\
\hline \multicolumn{10}{|l|}{ Group $1^{a}$} \\
\hline Maselli et al. 2013 [36] & 26 & 24 & $34.0 \pm 17.6$ & NR & 0 & NR & NR & $N R$ & $N R$ \\
\hline \multicolumn{10}{|l|}{ Group $2^{b}$} \\
\hline Braunstahl et al. 2013 [28] & 943 & 12 & $45.0 \pm 15.5$ & $N R$ & 16.6 & 8.4 & NR & $N R$ & 8.2 \\
\hline Özgür et al. 2013 [38] & 26 & 6 & $47.6 \pm 13.9$ & 0.23 & 0 & NR & $N R$ & $N R$ & $N R$ \\
\hline Vieira et al. 2014 [41] & 15 & 6 & $45.6 \pm 10.8$ & 0.15 & 26.66 & 6.66 & NR & 20.00 & NR \\
\hline Ancochea et al. 2014 [25] & 214 & 12 & $48.2 \pm 17.7$ & 0.43 & 7.9 & 4.2 & 2.3 & 1.9 & $N R$ \\
\hline
\end{tabular}

$F$ female, $M$ male, NR not reported, $R C T$ randomized controlled trials, $S D$ standard deviation

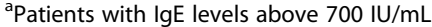

${ }^{b}$ Patients with IgE levels less or equal to $700 \mathrm{IU} / \mathrm{mL}$

drop-out rates and reasons. The overall drop-out rate was significantly higher in NEONet database. Patient's decision as a cause of dropping out showed the same trend. On the opposite drop-out rates due to lack of efficacy and adverse events do not significantly differ between NEONet and published Real-life studies.

In our study population the proportion of drop-outs does not significantly change in different treatment duration time intervals, as described in Fig. 1, which also shows the 95 \% Confidence Interval (CI) (blue lines). Furthermore, the logistic regression analysis confirms the lack of association between time and drop-out rate $(p=0.96)$.

Table 3 Comparison of drop-out rate mean values and reasons between RCTs and Real-life studies

\begin{tabular}{llll}
\hline & RCT & Real-life & $p$-value \\
\hline Drop-out & $11.65 \%$ & $17.50 \%$ & 0.0000 \\
Patient decision & $59.72 \%$ & $35.01 \%$ & 0.0000 \\
Lack of efficacy & $0.69 \%$ & $23.53 \%$ & 0.0000 \\
Adverse events & $22.92 \%$ & $12.04 \%$ & 0.0011 \\
Other causes & $116.67 \%$ & $29.41 \%$ & 0.0016 \\
\hline
\end{tabular}

\section{Discussion}

This review of publications on omalizumab in severe asthma demonstrated that there is a wide variability in both the drop-out rate and the reasons for discontinuing treatment. Drop-out rates appeared to be the lowest in RCTs-possibly because these studies are conducted under rigorously controlled conditions. In contrast, reallife studies, which are more closely aligned with routine clinical practice, cited markedly higher drop-out rates of up to $46 \%$. The NEONet database was more in line with the data from real-life studies with reported dropout rates of $32 \%$. Lack of efficacy was cited as one of the most common reasons for treatment discontinuation in both real-life studies and the NEONet database, while patient decision and adverse events primarily contributed to the drop-out rates observed in RCTs.

Poor treatment adherence is a well-known unmet need in patients with asthma. This is particularly the case with inhaled drugs $[2,13,43]$. Data regarding adherence patterns in patients treated with omalizumab are limited and the evidence is weakened by methodological differences across the studies [44]. However, despite the reported drop-out rates, adherence to omalizumab 
Table 4 Overall drop-out rate and main reasons for treatment discontinuation in the NEONet database

\begin{tabular}{|c|c|c|c|}
\hline Patient population $(n=221)$ & Drop-out patients $(70,32 \%)$ & Patients under treatment $(151,38 \%)$ & $p$-value \\
\hline Males, n (\%) & $25(35.71)$ & $68(45.03)$ & 0.0959 \\
\hline Females, n (\%) & $45(64.29)$ & $83(54.97)$ & \\
\hline Age-years, mean (SD) & $46.79(14.82)$ & $47.44(13.11)$ & 0.4904 \\
\hline Treatment duration-months, mean (SD) & $27.69(20.94)$ & $27.54(22.96)$ & 0.4992 \\
\hline \multicolumn{4}{|l|}{ Reason for drop-out, $n$ (\%) } \\
\hline Lack of efficacy & $18(26)$ & & \\
\hline Patient's decision discontinuation & $34(49)$ & & \\
\hline Efficacy & $4(6)$ & & \\
\hline Adverse events (local or systemic reactions) & $5(7)$ & & \\
\hline Onset of contraindications & $6(8)$ & & \\
\hline Patient moved to another referral center & $3(4)$ & & \\
\hline
\end{tabular}

NEONet North East Omalizumab Network, SD standard deviation

appears to be slightly higher than that observed with other anti-asthmatic drugs $[45,46]$. Therefore, omalizumab therapy has been proposed as an alternative for patients with poorly controlled asthma for whom adherence does not improve with conventional interventions [46]. One possible explanation is that compared with oral or inhaled treatments, omalizumab is regularly administered in a hospital setting under direct medical supervision thereby improving treatment adherence. Conversely, subcutaneous allergen immunotherapy, which is also regularly administered in a hospital setting to patients with respiratory allergy [47], is characterized by a lower adherence rate in comparison to omalizumab $[6,48]$. Of note, this immunotherapy is indicated in mild to moderate asthmatics with less severe symptoms [47]. On this basis, it could be argued that disease severity can positively affect adherence to treatment. A non-adherence rate of $44 \%$ in asthmatics with steroid-dependent asthma has been reported [14]. Furthermore, a recent observational study on omalizumab adherence identified a lower pre-bronchodilator percentage of predicted forced expiratory volume in $1 \mathrm{~s}\left(\mathrm{FEV}_{1}\right)$ as an independent predictor of good adherence [44].

Treatment discontinuation unrelated to medical reasons represents the major drawback of non-adherence. It implies there are preventable direct and indirect costs affecting both patient quality of life and health systems resources [49]. To the best of the authors' knowledge the

Table 5 Comparison of drop-out rate mean values and reasons between NEONet database and published Real-life studies

\begin{tabular}{llll}
\hline & NEONet & Real-life & $p$-value \\
\hline Drop-out & $31.67 \%$ & $17.50 \%$ & 0.0000 \\
Patient decision & $48.57 \%$ & $35.01 \%$ & 0.0160 \\
Lack of efficacy & $25.71 \%$ & $23.53 \%$ & 0.3475 \\
Adverse events & $7.14 \%$ & $12.04 \%$ & 0.1176 \\
Other causes & $18.57 \%$ & $29.41 \%$ & 0.0318 \\
\hline
\end{tabular}

drop-out rate among patients undergoing omalizumab treatment has never been systematically investigated as a primary outcome.

Overall, a lower rate of treatment discontinuation with a narrow range was observed in RCTs. This finding is to be expected if the setting of experimental studies is taken into account. In fact, the RCT protocol typically mandates regular patient assessment and a strict followup schedule, often with a shorter duration of follow-up in comparison with real-life studies. All of these factors may account for a lower withdrawal rate, which is also a methodological requirement in order to strengthen the final results $[15,50]$. Surprisingly, the reasons for patient drop outs were not reported in some RCTs [21, 24]. However, adverse effects and patient decision were responsible for most drop outs across the reviewed studies $[25,28,29,34,37,40]$. RCT protocols are usually demanding for patients and withdrawal due to inconvenience is not unexpected [48]. As far as adverse effects are concerned, RCT protocols include strict and careful monitoring of potential treatment-related adverse events that more frequently results in patient exclusion from the study than in the real-life setting $[50,51]$.

In the real-life studies, drop-out prevalence was characterized by a marked variability, ranging from $0 \%$ in four studies up to $45 \%$ in the remaining studies. Although the reasons for drop-outs were sporadically reported, in most cases lack of efficacy was responsible for treatment discontinuation. The proportion of patients who discontinued omalizumab due to a lack of efficacy was significantly higher in real-life studies than in RCTs. The different patient selection process may provide a possible explanation. In fact, patients' enrolment in RCTs relies on strict inclusion and exclusion criteria, which differs from the real-life setting.

A recent review from our group [51] has highlighted that sensitization to a perennial allergen is missing in 


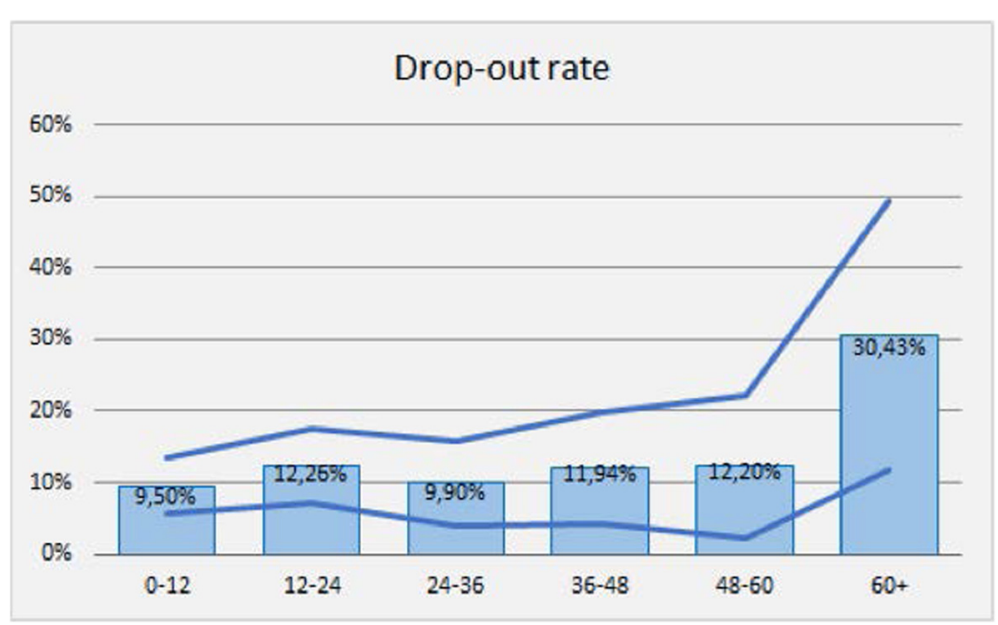

Fig. 1 Drop-out rates in different treatment duration time intervals (NEONet database; $n=221$ ). The blue lines indicate the $95 \%$ Confidence Interval (Cl)

more than $20 \%$ of patients undergoing omalizumab treatment, despite being included among the prescription criteria established by the European Medicines Agency (EMA) [52]. However, non-responders have also been described among patients matching all the EMA prescription criteria $[17,28]$, and the efficacy of omalizumab in non-atopic asthma is also supported by the literature [53]. Patient selection, particularly in the field of biological drugs for asthma, still represents a challenge $[54,55]$. The relevance of a number of biomarkers has been recently investigated and still fosters current research. The poor specificity of many molecules and the complex relationship between symptoms, exacerbations, response to drugs and underlying inflammation hampers the identification of univocal and standardized biomarkers predictive of clinical response [56, 57]. Such biomarkers are still lacking for omalizumab and for current and upcoming biological treatments for severe asthma $[55,58]$.

Nevertheless, patient selection is one of the most important aspects in managing biological drugs as they target a very specific mechanism in the pathophysiologic picture of the disease $[58,59]$.

Omalizumab has a good safety profile, both in the experimental and real-life setting. Only three studies, two RCTs [19, 22] and one real-life study [37], reported adverse events as the main cause of treatment discontinuation, without any significant differences in terms of drop-out rate. Of note, a local reaction at the injection site was the commonest adverse event. This finding suggests that tolerability is an important issue and consequently it has to be carefully considered; as evidenced with other treatments, it can significantly affect adherence [60]. Therefore, clinicians should discuss tolerability issues with their patients as part of a strategy aimed at improving adherence.
The results from the NEONet database were similar to those reported in published studies, although the overall drop-out rate seems to be higher in our study population. For project's policy, Referral Centers included in the NEONet collaboration are requested to strictly and regularly follow-up the patients, thus under this perspective our clinical practice is more similar to a RCT setting than to a pure real-life one. It may provide an explanation for our finding. However drop-out rates due to lack of efficacy and adverse events do not significantly differ between NEONet and published Real-life studies. The population sample was smaller in comparison with other real-life studies, however it is quite homogeneous, as the patients live in the same geographical area, and the centers share the same diagnostic work-up and patient selection criteria [17]. In the NEONet population, patient decision was the most common reason for dropping out. Although several reasons can influence patient choice, inconvenience may play the most relevant role $[6,14]$. In fact, the need for regular administration of omalizumab in hospital once or twice per month can strongly affect treatment adherence, as it has many implications such as work-absenteeism and economic burden. Under this perspective, patient's perception of clinical efficacy as well as lack of efficacy, has a crucial relevance as it may weaken the motivation of the patient for continuing treatment.

Interestingly, in our study population treatment length does not seem to affect drop-out rate. In fact, the proportion of drop-outs is similar in all the treatment duration time intervals (Fig. 1). Apparently the drop-out rate in the last interval is higher, but the small sample size in that range may account for this effect, as shown in the graph by the CI bars. Furthermore, the logistic regression analysis confirms the lack of association between time and drop-out rate $(p=0.96)$. Whether the length of treatment impacts on the adherence rate is not 
easy to evaluate in the published studies, due to the great variability in terms of study duration [25-42]. However the ideal treatment duration, as well as the identification of biomarkers that are accurate in predicting the clinical response are still lacking $[58,59]$. In fact, lack of efficacy, similarly to the published Real life studies [25-42], accounted for $26 \%$ of drop-outs among NEONet patients, despite all patients being fully matched with the current prescription criteria. In the real-life setting, many patient-related variables, such as smoking habits, comorbidities, and multi-drug treatments, may affect treatment efficacy and effectiveness [51, 61], even though prescription criteria are verified. In this scenario patient's education, in terms of awareness of the treatment and its implications, has an even more relevant role in preventing drop-outs and generally supporting adherence [62, 63].

Some limitations of our work deserve to be highlighted. Two variables potentially affecting the drop-out rate, lung function at baseline and prescribed medications other than Omalizumab, have not been extensively analyzed. In the case of the first determinant, few data are available in literature, however a lower forced expiratory volume in $1 \mathrm{~s}\left(\mathrm{FEV}_{1}\right)$ has been described as an independent predictor of good adherence [44]. Concerning the published studies included in the present review [16, 19-42], a systematic analysis of the lung function and its impact on drop-out rate is not easy relying on the available information, affected by great variability, or not mentioned at all. In our dataset analysis, GETE questionnaire for the evaluation of clinical efficacy indirectly includes the impact of treatment on lung function. As lack of efficacy is one of the main drop-out reasons, it could be hypothesized that a poor lung function at baseline, maintained during the treatment, may act as a determinant of poor adherence.

A great variability, or the lack of detailed information, also regards the prescribed medications other than Omalizumab [16, 19-42] and hampers an extensive analysis of this further drop-out determinant. The scenario is even more complex if we consider the amount of drugs prescribed for comorbidities. Such analysis is out of the aim of our paper and requires an adequately sized population sample. However, according to the literature adherence to omalizumab appears to be slightly higher than that observed with other antiasthmatic drugs, independently of other medication prescribed at the same time $[45,46]$.

A second limitation of our work relates to the study design itself; in real-life observational studies it is difficult to avoid or properly assess bias, and conclusions are not easily applicable across a generalized population. Furthermore, often only a descriptive analysis has been provided. Nevertheless, to our knowledge treatment discontinuation rate has never been systematically investigated as a primary outcome in a real-life setting and awareness of the most common reasons for patient withdrawal may help in finalizing some practical suggestions to improve adherence in routine clinical practice.

\section{Conclusion}

In conclusion, the risk of treatment discontinuation is a significant drawback for omalizumab therapy and this warrants consideration when prescribing. The reasons for dropping out have to be carefully taken into consideration when planning specific long-term strategies in order to prevent treatment withdrawal.

\section{Acknowledgements}

The authors would like to thank Anna Battershill who provided English editing and styling of the manuscript on behalf of Springer Healthcare Communications. The authors would also like to thank the following members of the North East Omalizumab Network Study Group for their contribution to the manuscript: C. Barp (Belluno), L. Bonazza (Bolzano), MA Crivellaro (Padova), A Dama (Verona), G. Donazzan (Bolzano), G. Idotta (Cittadella, PD), C. Lombardi (Brescia), M. Nalin (Rovigo), C. Pomari (Negrar, VR), M. Schiappoli (Verona).

\section{Funding}

English editing and styling of the manuscript was provided by Springer Healthcare Communications and funded by Novartis (Italy).

Availability of data and materials

Data requests can be sent to Dr Marco Caminati.

\section{Authors' contributions}

$M C$ and GS conceived and designed the study, and drafted the manuscript. GS coordinated the data collection. FCB, GG, ST, MO, CM, GF, EB, FM, AR and AV participated in the data collection and contributed to data analysis and interpretation. All authors read and approved the final manuscript.

\section{Competing interests}

The authors declare no relevant affiliations or financial involvement with any organization or entity with a financial interest in or financial conflict with the subject matter or materials discussed in the manuscript.

\section{Consent for publication}

Not applicable.

\section{Ethics approval and consent to participate}

The Verona and Rovigo provinces Institutional Review Board and Ethics Committee approved this study (approval number: 223CESC). All participants gave written consent to take part in the study.

\section{Author details}

${ }^{1}$ Asthma Center and Allergy Unit, Verona General and University Hospital, Verona, Italy. ${ }^{2}$ Respiratory Pathophysiology Division, University-City Hospital of Padua, Padua, Italy. ${ }^{3}$ Department of Cardiologic, Thoracic and Vascular Sciences, University of Padua, Padua, Italy. ${ }^{4}$ Respiratory Unit, Orlandi General Hospital, Bussolengo, Verona, Italy. ${ }^{5}$ Unit of Occupational Medicine, Verona General and University Hospital, Verona, Italy. ${ }^{6}$ Respiratory Unit, Mater Salutis Hospital, Legnago, Verona, Italy. ${ }^{7}$ Pulmonary Unit, Verona University and General Hospital, Verona, Italy. ${ }^{8}$ Respiratory pathology Unit, Arzignano General Hospital, Vicenza, Italy. ${ }^{9}$ Pulmonary Unit, Pordenone General Hospital, Pordenone, Italy.

Received: 23 November 2015 Accepted: 18 August 2016

Published online: 25 August 2016 


\section{References}

1. Osterberg L, Blaschke T. Adherence to medication. N Engl J Med. 2005;353(5):487-97.

2. Lasmar L, Camargos P, Champs NS, Fonseca MT, Fontes MJ, Ibiapina C, et al. Adherence rate to inhaled corticosteroids and their impact on asthma control. Allergy. 2009;64(5):784-9.

3. Christensen AJ. Patient's adherence to medical treatment regimens: bridging the gap between behavioural science and biomedicine. Current Perspectives in Psycology Series. New Haven: Yale University Press; 2004.

4. Cutler DM, Everett W. Thinking outside the pillbox-medication adherence as a priority for health care reform. N Engl J Med. 2010;362(17):1553-5.

5. Cutler DM, Long G, Berndt ER, Royer J, Fournier AA, Sasser A, et al. The value of antihypertensive drugs: a perspective on medical innovation. Health Aff (Millwood). 2007;26(1):97-110.

6. Reisacher WR, Visaya JM. Patient adherence to allergy immunotherapy. Curr Opin Otolaryngol Head Neck Surg. 2013;21(3):256-62.

7. Sabatè E. Adherence to long term therapies: evidence for action. Geneva: World Health Organization; 2003.

8. DiMatteo MR. Variations in patients' adherence to medical recommendations: a quantitative review of 50 years of research. Med Care 2004;42(3):200-9.

9. Braido F, Baiardini I, Blasi F, Pawankar R, Canonica GW. Adherence to asthma treatments: 'we know, we intend, we advocate'. Curr Opin Allergy Clin Immunol. 2015;15(1):49-55.

10. Chowdhury R, Khan H, Heydon E, Shroufi A, Fahimi S, Moore C, et al. Adherence to cardiovascular therapy: a meta-analysis of prevalence and clinical consequences. Eur Heart J. 2013;34(38):2940-8.

11. Kronish IM, Ye S. Adherence to cardiovascular medications: lessons learned and future directions. Prog Cardiovasc Dis. 2013;55(6):590-600.

12. Bender DG. Overcoming barriers to nonadherence in asthma treatment. J Allergy Clin Immunol. 2002;109(6 Suppl):S554-9.

13. Sumino K, Cabana MD. Medication adherence in asthma patients. Curr Opin Pulm Med. 2013;19(1):49-53.

14. Gamble J, Stevenson M, McClean E, Heaney LG. The prevalence of nonadherence in difficult asthma. Am J Respir Crit Care Med. 2009:180(9):817-22.

15. Passalacqua G, Baiardini I, Senna G, Canonica GW. Adherence to pharmacological treatment and specific immunotherapy in allergic rhinitis. Clin Exp Allergy. 2013;43(1):22-8.

16. Busse W, Corren J, Lanier BQ, McAlary M, Fowler-Taylor A, Cioppa GD, et al. Omalizumab, anti-lgE recombinant humanized monoclonal antibody, for the treatment of severe allergic asthma. J Allergy Clin Immunol. 2001;108(2):184-90.

17. Caminati M, Senna G, Chieco Bianchi F, Marchi MR, Vianello A, Micheletto C, et al. Omalizumab management beyond clinical trials: the added value of a network model. Pulm Pharmacol Ther. 2014;29(1):74-9.

18. Lloyd A, Turk F, Leighton T, Canonica GW. Psychometric evaluation of global evaluation of treatment effectiveness: a tool to assess patients with moderate-to-severe allergic asthma. J Med Econ. 2007;10:285-96.

19. Ayres JG, Higgins B, Chilvers ER, Ayre G, Blogg M, Fox H. Efficacy and tolerability of anti-immunoglobulin $\mathrm{E}$ therapy with omalizumab in patients with poorly controlled (moderate-to-severe) allergic asthma. Allergy. 2004;59(7):701-8.

20. Hanania NA, Alpan O, Hamilos DL, Condemi JJ, Reyes-Rivera I, Zhu J, et al. Omalizumab in severe allergic asthma inadequately controlled with standard therapy: a randomized trial. Ann Intern Med. 2011;154(9):573-82.

21. Holgate ST, Chuchalin AG, Hebert J, Lötvall J, Persson GB, Chung KF, et al. Efficacy and safety of a recombinant anti-immunoglobulin $E$ antibody (omalizumab) in severe allergic asthma. Clin Exp Allergy. 2004;34(4):632-8.

22. Humbert M, Beasley R, Ayres J, Slavin R, Hebert J, Bousquet J, et al. Benefits of omalizumab as add-on therapy in patients with severe persistent asthma who are inadequately controlled despite best available therapy (GINA 2002 step 4 treatment): INNOVATE. Allergy. 2005;60(3):309-16.

23. Soler M, Matz J, Townley R, Buhl R, O'Brien J, Fox H, et al. The anti-lgE antibody omalizumab reduces exacerbations and steroid requirement in allergic asthmatics. Eur Respir J. 2001;18(2):254-61.

24. Vignola AM, Humbert M, Bousquet J, Boulet LP, Hedgecock S, Blogg M, et al. Efficacy and tolerability of anti-immunoglobulin E therapy with omalizumab in patients with concomitant allergic asthma and persistent allergic rhinitis: SOLAR. Allergy. 2004;59(7):709-17.
25. Ancochea J, Chivato T, Casan P, Picado C, Herraez L, Casafont J. Profile of patients treated with omalizumab in routine clinical practice in Spain. Allergol Immunopathol (Madr). 2014;42(2):102-8.

26. Barnes N, Menzies-Gow A, Mansur AH, Spencer D, Percival F, Radwan A, et al. Effectiveness of omalizumab in severe allergic asthma: a retrospective UK real-world study. J Asthma. 2013:50(5):529-36.

27. Bavbek S, Aydin O, Kepil Özdemir S, Yilmaz I, Celik GE, Demirel YS, et al. Therapy with omalizumab in patients with severe persistent allergic asthma: a real life data in Turkey. Tuberk Toraks. 2010;58(4):425-34.

28. Braunstahl GJ, Chen CW, Maykut R, Georgiou P, Peachey G, Bruce J. The expeRience registry: the 'real-world' effectiveness of omalizumab in allergic asthma. Respir Med. 2013;107(8):1141-51.

29. Brusselle G, Michils A, Louis R, Dupont L, Van de Maele B, Delobbe A, et al. "Real-life" effectiveness of omalizumab in patients with severe persistent allergic asthma: The PERSIST study. Respir Med. 2009;103(11):1633-42.

30. Cazzola M, Camiciottoli G, Bonavia M, Gulotta C, Ravazzi A, Alessandrini A, et al. Italian real-life experience of omalizumab. Respir Med. 2010;104(10):1410-6.

31. Chen H, Eisner MD, Haselkorn T, Trzaskoma B. Concomitant asthma medications in moderate-to-severe allergic asthma treated with omalizumab. Respir Med. 2013;107(1):60-7.

32. Eisner MD, Zazzali JL, Miller MK, Bradley MS, Schatz M. Longitudinal changes in asthma control with omalizumab: 2-year interim data from the EXCELS Study. J Asthma. 2012;49(6):642-8.

33. Grimaldi-Bensouda L, Zureik M, Aubier M, Humbert M, Levy J, Benichou J, et al. Does omalizumab make a difference to the real-life treatment of asthma exacerbations?: Results from a large cohort of patients with severe uncontrolled asthma. Chest. 2013;143(2):398-405.

34. Korn S, Thielen A, Seyfried S, Taube C, Kornmann O, Buhl R. Omalizumab in patients with severe persistent allergic asthma in a real-life setting in Germany. Respir Med. 2009;103(11):1725-31.

35. Lafeuille MH, Dean J, Zhang J, Duh MS, Gorsh B, Lefebvre P. Impact of omalizumab on emergency-department visits, hospitalizations, and corticosteroid use among patients with uncontrolled asthma. Ann Allergy Asthma Immunol. 2012:109(1):59-64.

36. Maselli DJ, Singh H, Diaz J, Peters Jl. Efficacy of omalizumab in asthmatic patients with lgE levels above $700 \mathrm{IU} / \mathrm{mL}$ : a retrospective study. Ann Allergy Asthma Immunol. 2013;110(6):457-61.

37. Molimard M, de Blay F, Didier A, Le Gros V. Effectiveness of omalizumab (Xolair) in the first patients treated in real-life practice in France. Respir Med. 2008;102(1):71-6.

38. Özgür ES, Ozge C, Ilvan A, Nayci SA. Assessment of long-term omalizumab treatment in patients with severe allergic asthma long-term omalizumab treatment in severe asthma. J Asthma. 2013;50(6):687-94.

39. Tzortzaki EG, Georgiou A, Kampas D, Lemessios M, Markatos M, Adamidi T, et al. Long-term omalizumab treatment in severe allergic asthma: the South-Eastern Mediterranean "real-life" experience. Pulm Pharmacol Ther. 2012;25(1):77-82.

40. Vennera Mdel C, Perez De Llano L, Bardagi S, Ausin P, Sanjuas C, Gonzalez $\mathrm{H}$, et al. Omalizumab therapy in severe asthma: experience from the Spanish registry-some new approaches. J Asthma. 2012;49(4):416-22.

41. Vieira T, de Oliveira JF, da Graca Castel-Branco M. Short and long-term quality of life and asthma control with omalizumab therapy in a real life setting in Portugal. Allergol Immunopathol (Madr). 2014;42(1):3-10.

42. Wittchen HU, Muhlig S, Klotsche J, Buhl R, Kardos P, Ritz T, et al. Omalizumab versus 'usual care': results from a naturalistic longitudinal study in routine care. Int Arch Allergy Immunol. 2012;159(1):83-93.

43. Wu AC, Butler MG, Li L, Fung V, Kharbanda EO, Larkin EK, et al. Primary adherence to controller medications for asthma is poor. Ann Am Thorac Soc. 2015;12(2):161-6.

44. Janson SL, Solari PG, Trzaskoma B, Chen H, Haselkorn T, Zazzali JL. Omalizumab adherence in an observational study of patients with moderate to severe allergic asthma. Ann Allergy Asthma Immunol. 2015;114(6):516-21. e2.

45. Broder MS, Chang EY, Ory C, Kamath T, Sapra S. Adherence and persistence with omalizumab and fluticasone/salmeterol within a managed care population. Allergy Asthma Proc. 2009:30(2):148-57.

46. Hendeles L, Khan YR, Shuster JJ, Chesrown SE, Abu-Hasan M. Omalizumab therapy for asthma patients with poor adherence to inhaled corticosteroid therapy. Ann Allergy Asthma Immunol. 2015;114(1):58-62. e2. 
47. Zuberbier T, Bachert C, Bousquet PJ, Passalacqua G, Walter Canonica G, Merk H, et al. GA(2) LEN/EAACl pocket guide for allergen-specific immunotherapy for allergic rhinitis and asthma. Allergy. 2010;65(12):1525-30.

48. Senna G, Caminati M, Lockey RF. Allergen immunotherapy adherence in the real world: How bad is it and how can it be improved? Curr Treat Options Allergy. 2015;2:39-53.

49. Schlender A, Alperin PE, Grossman HL, Sutherland ER. Modeling the impact of increased adherence to asthma therapy. PLoS One. 2012;7(12):e51139.

50. Saturni S, Bellini F, Braido F, Paggiaro P, Sanduzzi A, Scichilone N, et al. Randomized Controlled Trials and real life studies. Approaches and methodologies: a clinical point of view. Pulm Pharmacol Ther. 2014;27(2):129-38.

51. Caminati M, Senna G, Guerriero M, Dama AR, Chieco-Bianchi F, Stefanizzi G, et al. Omalizumab for severe allergic asthma in clinical trials and real-life studies: what we know and what we should address. Pulm Pharmacol Ther. 2015;31:28-35

52. European Medicines Agency; Xolair: EPAR - Product Information. http://www.ema.europa.eu/ema/index.jsp?curl=pages/medicines/ human/medicines/000606/human_med_001162. jsp\&mid=WCOb01ac058001d124. Accessed 20 June 2015.

53. Domingo C, Pomares X, Angril N, Rudi N, Amengual MJ, Mirapeix RM. Effectiveness of omalizumab in non-allergic severe asthma. J Biol Regul Homeost Agents. 2013;27(1):45-53.

54. Arron JR, Choy DF, Scheerens H, Matthews JG. Noninvasive biomarkers that predict treatment benefit from biologic therapies in asthma. Ann Am Thorac Soc. 2013;10(Suppl):S206-13.

55. Bartminski G, Crossley M, Turcanu V. Novel biomarkers for asthma stratification and personalized therapy. Expert Rev Mol Diagn. 2015;15(3):415-30.

56. Caffarelli C, Calcinai E, Rinaldi L, Povesi Dascola C, Terracciano L, Corradi M. Hydrogen peroxide in exhaled breath condensate in asthmatic children during acute exacerbation and after treatment. Respiration. 2012;84(4):291-8.

57. Caffarelli C, Dascola CP, Peroni D, Ricò S, Stringari G, Varini M, Folesani G, Corradi M. Airway acidification in childhood asthma exacerbations. Allergy Asthma Proc. 2014;35(3):51-6

58. Hilvering B, Pavord ID. What goes up must come down: biomarkers and novel biologicals in severe asthma. Clin Exp Allergy. 2015;45(7):1162-9.

59. Fajt ML, Wenzel SE. Asthma phenotypes and the use of biologic medications in asthma and allergic disease: the next steps toward personalized care. J Allergy Clin Immunol. 2015;135(2):299-310. quiz 1.

60. Senna G, Caminati M, Canonica GW. Safety and tolerability of sublingual immunotherapy in clinical trials and real life. Curr Opin Allergy Clin Immunol. 2013;13(6):656-62.

61. Battaglia S, Basile M, Spatafora M, Scichilone N. Are asthmatics enrolled in randomized trials representative of real-life outpatients? Respiration. 2015;89(5):383-9.

62. Eakin MN, Rand CS. Improving patient adherence with asthma selfmanagement practices: what works? Ann Allergy Asthma Immunol. 2012;109(2):90-2.

63. Shams MR, Fineman SM. Asthma adherence: how can we help our patients do it better? Ann Allergy Asthma Immunol. 2014;112(1):9-12.

\section{Submit your next manuscript to BioMed Central and we will help you at every step:}

- We accept pre-submission inquiries

- Our selector tool helps you to find the most relevant journal

- We provide round the clock customer support

- Convenient online submission

- Thorough peer review

- Inclusion in PubMed and all major indexing services

- Maximum visibility for your research

Submit your manuscript at www.biomedcentral.com/submit

) Biomed Central 